\title{
Influence of sputtering deposition parameters on electrical and optical properties of aluminium-doped zinc oxide thin films for photovoltaic applications
}

\author{
Ewelina Krawczak ${ }^{1, *}$, Agata $\mathrm{Zdyb}^{1}$, Slawomir Gulkowski ${ }^{1}$, Alain Fave $^{2}$, and Erwann \\ Fourmond $^{2}$ \\ ${ }^{1}$ Lublin University of Technology, Faculty of Environmental Engineering, Institute of Renewable \\ Energy Engineering, ul. Nadbystrzycka 40B, 20-618 Lublin, Poland \\ ${ }^{2}$ Institut des Nanotechnologies de Lyon -INL, UMR CNRS 5270 CNRS, Université de Lyon, INSA de \\ Lyon, F-69621 Villeurbanne, France
}

\begin{abstract}
Transparent Conductive Oxides (TCOs) characterized by high visible transmittance and low electrical resistivity play an important role in photovoltaic technology. Aluminum doped zinc oxide (AZO) is one of the TCOs that can find its application in thin film solar cells (CIGS or CdTe PV technology) as well as in other microelectronic applications. In this paper some optical and electrical properties of $\mathrm{ZnO}: \mathrm{Al}$ thin films deposited by $\mathrm{RF}$ magnetron sputtering method have been investigated. AZO layers have been deposited on the soda lime glass substrates with use of variable technological parameters such as pressure in the deposition chamber, power applied and temperature during the process. The composition of AZO films has been investigated by EDS method. Thickness and refraction index of the deposited layers in dependence on certain technological parameters of sputtering process have been determined by spectroscopic ellipsometry. The measurements of transmittance and sheet resistance were also performed.
\end{abstract}

\section{Introduction}

Transparent Conductive Oxides (TCO) films play a significant role as an transparent electrode in the optoelectronic and photovoltaic devices, especially in thin films solar cells [1-6]. The most widely used TCO, both in research and industry, are Indium Tin Oxide (ITO) films, because they are characterized by a good electrical and optical properties. However, future availability and cost issues require to replace it by another TCO. The main goal of the studies on TCO structures is to obtain high transmittance of the material, above $80 \%$ over a large spectral range, with resistivity below $10^{-3} \Omega \cdot \mathrm{cm}$ and wide band gap [6,7]. In order to improve the efficiency in some optoelectronic applications the optical transparency of TCO films should be extended to the ultraviolet and infrared spectral ranges. One of the TCO materials that is widely investigated in recent years is zinc-oxide $\mathrm{ZnO}$, which is non-toxic,

\footnotetext{
* Corresponding author: e.krawczak@pollub.pl
} 
abundant and relatively cheap material. Modified $\mathrm{ZnO}$ material, for example aluminum doped zinc oxide (AZO, $\mathrm{ZnO}: \mathrm{Al}$ ) can be a substitute of ITO in the top electrode or can be a part of double layer back contact in the thin film solar cell. It is also of high importance to obtain $\mathrm{ZnO}$ structures doped with the third group element, such as $\mathrm{B}, \mathrm{Ga}$, In or $\mathrm{Al}$, since it leads to improvement of electrical conductivity of the layer [8].

Apart from magnetron sputtering belonging to physical vapour deposition methods (PVD), variety of techniques used for $\mathrm{ZnO}$ :Al production can be distinguished: sol-gel deposition, spray coating, pulsed laser deposition (PLD) and aerosol-assisted MOCVD technique [9-14]. In order to achieve aluminum doped zinc oxide layers with good electrooptical properties on inflexible or flexible substrate [15], RF and DC magnetron deposition or co-sputtering deposition can be used [16-21]. Numerous of technological parameters have the influence on the quality of the obtained thin films such as: power applied to the cathode, the pressure in the chamber during deposition process, target-substrate distance, type and flow of the process gases, substrate temperature or even positioning of the substrate relative to the target.

In the present study $\mathrm{ZnO}$ :Al layers were obtained by RF magnetron sputtering method on clean soda lime glass substrates and their composition was determined by EDS (Energy Dispersive Spectroscopy) method. Ellipsometry measurements provided information on the thickness of the films produced under different conditions of the deposition process. Basing on these data the rate of growth was estimated and the influence of AZO thickness on index of refraction was studied. The refractive index $(n)$ of semiconducting material like AZO is one of the optical constants that is essential in optoelectronic studies and applications. In design of thin film photovoltaic devices determination of $n$ for an outer transparent electrode is of high importance since it influences the amount of light that propagates into the $p-n$ junction and can be potentially utilized. Spectroscopic transmittance measurement confirmed very good transparency of $\mathrm{ZnO}: \mathrm{Al}$ films. Resistivity of the obtained layers, also determined in this work, plays an important role especially if they are meant to be applied as an electrode in thin film devices.

\section{Experimental}

The transparent conductive $\mathrm{Al}$ doped $\mathrm{ZnO}$ films were deposited onto soda lime glass (SLG) substrate using RF (Radio Frequency) magnetron sputtering method. Alliance Concept AC450 magnetron sputtering system was used in the experiment in order to find optimum parameters of the sputtering process. The radio frequency (RF) power was applied to 4 inches in diameter and $6 \mathrm{~mm}$ thick ceramic target composed by $98 \mathrm{wt} . \% \mathrm{ZnO}$ and 2 wt.\% $\mathrm{Al}$ with purity of $99.99 \%$, purchased from BIMO Tech. Before the process soda lime glass substrates were ultrasonically and chemically cleaned in detergent, isopropyl alcohol, ethanol, deionized water and then dried in a nitrogen gas. The clean substrate was immediately mounted in the magnetron deposition chamber. Substrates were placed under the target directly onto unheated work holder, which is presented in Fig. 1. The static mode of substrate holder was used. The target - substrate distance was equal to $90 \mathrm{~mm}$. In this work AZO films were obtained at room temperature. The substrate holder temperature was kept at constant level during the deposition process due to water cooling system. 


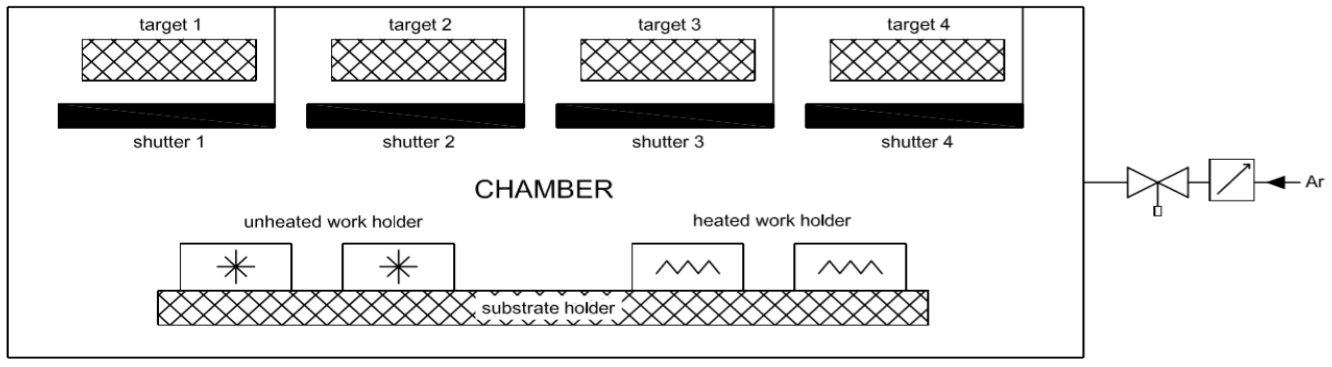

Fig. 1. The inside of the magnetron sputtering system chamber.

The magnetron chamber was evacuated to the base pressure of $1.0 \times 10^{-2} \mathrm{~Pa}$ and then presputtering process was carried out to clean the target surface and remove encountered impurities. Stability improvement of sputtering conditions was also achieved at the beginning. The RF power during the films deposition process varied in the range of $120-200 \mathrm{~W}\left(1.5-2.5 \mathrm{~W} / \mathrm{cm}^{2}\right)$. The working pressure was stabilized at $1.57 \mathrm{~Pa}$ by flow of the pure Ar gas, which was set at $20 \mathrm{sccm}$. EDS detector was applied to achieve EDS profile and analyze energy spectra of the layers. Film thickness and refractive index were measured by spectroscopic ellipsometer Jobin-Yvon Horiba UVISEL model, working between 1.5 and $5 \mathrm{eV}$ (around 830 to $250 \mathrm{~nm}$ wavelength) with use of new amorphous model. The sheet resistance of the obtained samples was measured at room temperature using RM3000+ four point probe equipment from Jandel Engineering Limited.

\section{Results}

Figure 2 shows the example of EDS diagram of the $\mathrm{ZnO}: \mathrm{Al}$ deposited film. The qualitative analysis was made to obtain the mass and weight fractions of the elements existing in the prepared film. The composition of elements was as follows: $\mathrm{Zn} \mathrm{w.} \%-68.06$, O w.\% -29.65 , $\mathrm{Al}$ w. $\%-2.29$. It should be noticed that all prepared samples revealed the similar composition and irregularities were not detected.

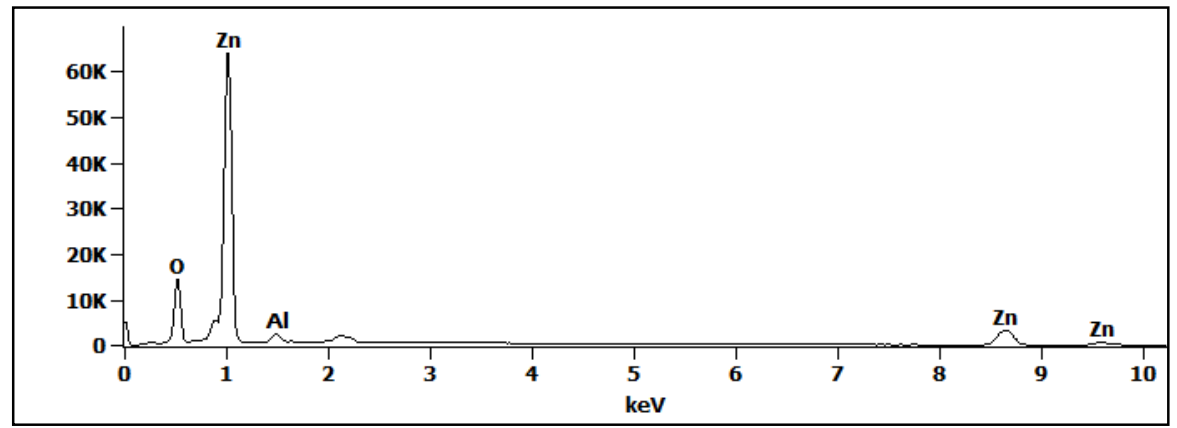

Fig. 2. EDS profile of the $\mathrm{Al}$ doped $\mathrm{ZnO}$ sample prepared using magnetron sputtering system.

Several series of samples were prepared at three different values of deposition power under the same working pressure at room temperature during different sputtering time. The influence of the sputtering time on the thickness of the AZO films is presented in Fig. 3 for three different deposition powers: $1.5 \mathrm{~W} / \mathrm{cm}^{2}, 2 \mathrm{~W} / \mathrm{cm}^{2}, 2.5 \mathrm{~W} / \mathrm{cm}^{2}$. Ellipsometry measurements provided the following thickness values obtained for 30, 40 and $45 \mathrm{~min}$ deposition time, respectively: $286 \mathrm{~nm}, 413 \mathrm{~nm}, 463 \mathrm{~nm}$ (power $1.5 \mathrm{~W} / \mathrm{cm}^{2}$ ), $322 \mathrm{~nm}$, 
$539 \mathrm{~nm}, 622 \mathrm{~nm}$ (power $2 \mathrm{~W} / \mathrm{cm}^{2}$ ), $490 \mathrm{~nm}, 823 \mathrm{~nm}, 1178 \mathrm{~nm}$ (power $2.5 \mathrm{~W} / \mathrm{cm}^{2}$ ). The dependence shows that the thickness of the deposited films increases for higher power values and longer deposition time. The estimated growth rate values change from average $8.8 \mathrm{~nm} \cdot \mathrm{min}^{-1}$ for the power of $1.5 \mathrm{~W} / \mathrm{cm}^{2}, 11 \mathrm{~nm} \cdot \mathrm{min}^{-1}$ for $2 \mathrm{~W} / \mathrm{cm}^{2}$ to $18 \mathrm{~nm} \cdot \mathrm{min}^{-1}$ for $2.5 \mathrm{~W} / \mathrm{cm}^{2}$. One can note that linearity is better for high power value. The highest sputtering ratio equal to $19.7 \mathrm{~nm} \cdot \mathrm{min}^{-1}$ was obtained for the longest deposition time.

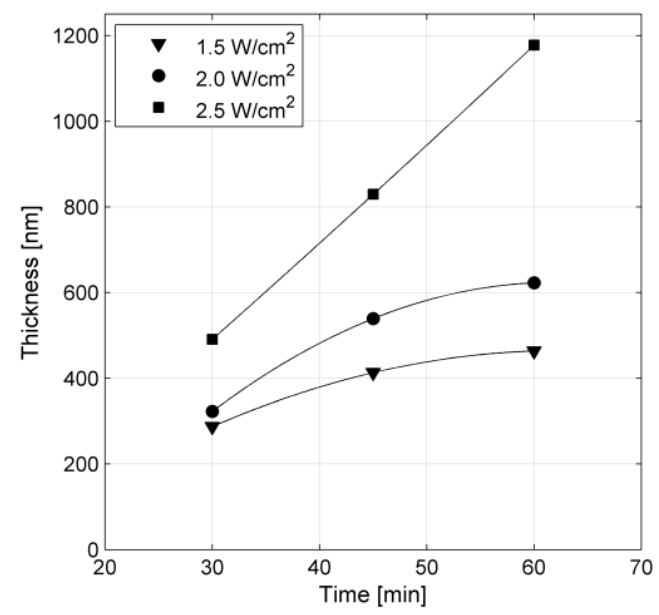

Fig. 3. The thickness of the obtained AZO films as the function of the deposition time for different magnetron power.

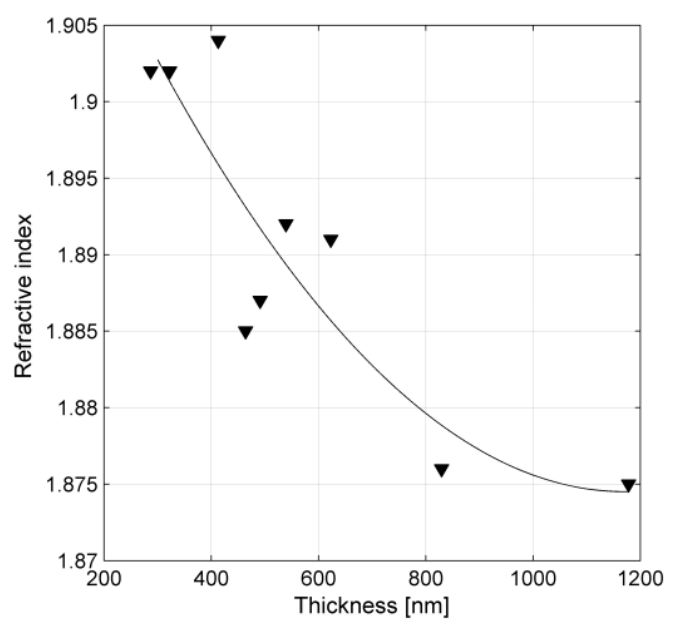

Fig. 4. The refractive index of $\mathrm{ZnO}: \mathrm{Al}$ films as a function of the thickness, measured at $\lambda=633 \mathrm{~nm}$.

The refractive index ( $n$ ) was obtained from ellipsometry measurements for AZO films of different thickness. Index of refraction values are shown in Fig. 4 as a function of the thickness of the deposited layers at wavelength of $633 \mathrm{~nm}$. The obtained $n$ values decrease from 1.905 to 1.875 with increasing thickness of the films and are lower than those for $\mathrm{ZnO}$ i.e. 1.95-2.1 in visible range [22]. The observed relation corresponds to dependency reported in the literature [23]. Basing on the refractive index values transmittance and reflectance at normal incidence can be determined according to Fresnel formulas (Eq. 1, 2): 


$$
\begin{gathered}
T=\frac{4 n_{1} n_{2}}{\left(n_{1}+n_{2}\right)^{2},} \\
R=\left(\frac{n_{2}-n_{1}}{n_{1}+n_{2}}\right)^{2},
\end{gathered}
$$

where $n_{1}=1$ in the air, $n_{2}-$ index of refraction of the layer. Taking into account $n_{2}=1.905$ or $n_{2}=1.875$ the transmittance is equal to $90.3 \%$ and $90.7 \%$ and reflectance values to $9.7 \%$ and $9.3 \%$ respectively. Experimentally obtained transmittance spectra presented in Fig. 5 reveal mean values above $90 \%$ both for the lowest and highest film thickness. Very good transmittance and homogeneity of the $\mathrm{ZnO}$ :Al films were also exhibited before [24].

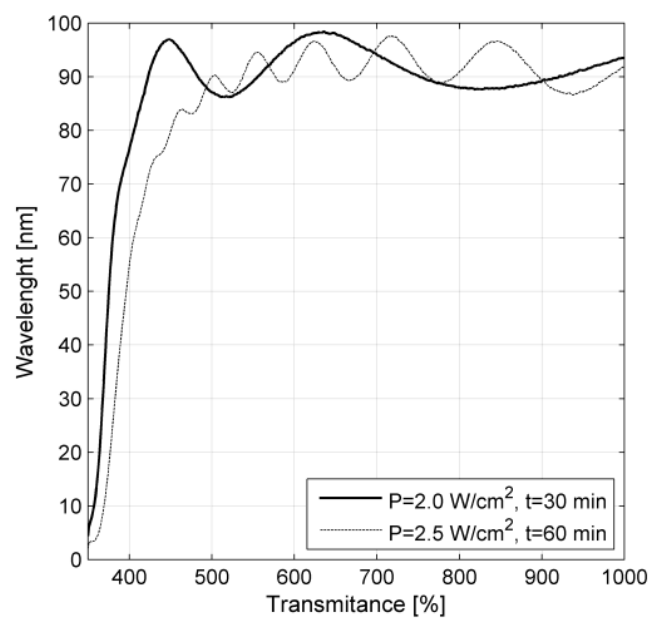

Fig. 5. Transmitance spectra of $\mathrm{ZnO}: \mathrm{Al}$ layers of thickness $322 \mathrm{~nm}$ and $1178 \mathrm{~nm}$ (pure glass transmittance is subtracted).

Electrical properties of AZO films were also subject of our investigations. The correlation between sheet resistance and thickness of the deposited AZO layers is shown in Fig. 6. The sheet resistance decreases with increasing thickness of the layers. According to all obtained results these dependences are analogues for all RF powers used under the same pressure of the process. Here we considered the films obtained at the discharged power of $2.5 \mathrm{~W} / \mathrm{cm}^{2}$ since in this case we achieved the lowest range of the resistance value. As expected, the sheet resistance decreases very significantly as the thickness of AZO film increases from the $491 \mathrm{~nm}$ to $830 \mathrm{~nm}$. Beyond this range of thickness the resistance drop is not so considerable with further AZO thickness increase. According to all obtained results these dependences are analogues for all RF powers used under the same pressure of the process. Taking into account prospect applications of $\mathrm{ZnO}$ :Al layers, the sheet resistance value is expected to lay below $50 \Omega /$ sq. The improvement of the results we obtained is probably possible by lowering the chamber pressure or heating of the samples. 


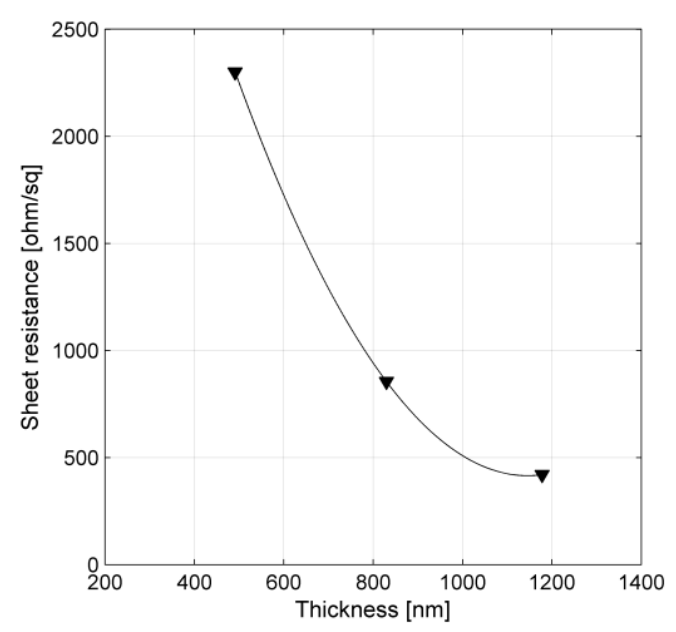

Fig. 6. Sheet resistance of $\mathrm{ZnO}: \mathrm{Al}$ films as a function of the thickness.

\section{Summary}

$\mathrm{ZnO}$ layers doped with about $2.3 \mathrm{w} . \% \mathrm{Al}$ were obtained in magnetron sputtering system and their properties were studied. The growth rate during deposition was estimated to be in the range of $8.8-18 \mathrm{~nm} / \mathrm{min}$ depending on the magnetron power and time of the sputtering process. Refractive index of AZO films is directly related to deposited film thickness and changes from 1.905 to 1.875 for thicker layers. These values were used to calculate transmittance and reflectance according to Fresnel formula, which together with experimental data, allowed confirming good transparency of the layers. It has been also shown that higher power applied to the cathode material results in the lower resistivity of the thin film so the sheet resistance drops below $500 \Omega / \mathrm{sq}$ for the power of $2.5 \mathrm{~W} / \mathrm{cm}^{2}$ used during deposition. Further conductivity improvements are necessary to make the produced AZO films useful in photovoltaic applications.

\section{References}

1. H.J. Cho, S.U. Lee, B. Hong, Y.D. Shin, J.Y. Ju, H.D. Kim, M.Park, W.S. Choi, Thin Solid Films 518, 2941-2944 (2010)

2. J. Muller, B. Rech, J. Springer, Mi. Vanecek, Sol. Energy 77, 917-930 (2004)

3. J.J. Ding, H.X. Chen, S.Y. Ma, Physica E 42, 1861-1864 (2010)

4. S.J. Tark, M.G. Kang, S. Park, J.H. Jang, J.C. Lee, W. M. Kim, J.S. Lee, D. Kim, Curr. Appl. Phys. 9, 1318 (2009)

5. W. Beyer, J. Hüpkes, H. Stiebig, Thin Solid Films 516, 147-154 (2007)

6. J. Yoo, J. Lee, S. Kim, K. Yoon, I.J. Park, S.K. Dhungel, B. Karunagaran, D. Mangalaraj, J. Yi, Thin Solid Films 480-481, 213-217 (2005)

7. B.G. Choi, I.H. Kim, D.H. Kim, K.S. Lee, T.S. Lee, B. Cheong, Y.-J. Baik, W.M. Kim, J. Eur. Ceram. Soc. 25, 2161-2165 (2005)

8. P. Nunes, E. Fortunato, P. Tonello, F. Braz Fernandes, P. Vilarinho, R. Martins, Vacuum 64, 281-285 (2002) 
9. S. Kuprenaite, A. Abrutis, V. Kubilius, T. Murauskas, Z. Saltyte, V. Plausinaitiene, Thin Solid Films 559, 156-164 (2016)

10. T. Schuler, T. Krajewski, I. Grobelsek, M. A. Aegerter, Thin Solid Films 502, 67-71 (2006)

11. T. Schuler, M.A. Aegerter, Thin Solid Films 351, 125-131 (1999)

12. S. Kuprenaite, T. Murauskas, A. Abrutis, V. Kubilius, Z. Saltyte, V. Plausinaitiene, Surf. Coat. Tech. 599, 19-26 (2016)

13. C.G. Granqvist, Sol. Energy Mat. Sol. C 91, 1529-1598 (2007)

14. Y. Liu, L. Zhao, J. Lian, Vacuum 81, 18-21 (2006)

15. W. Li, H. Hao, M. He, J. Xing, H. Gao, J. Dong, Surf. Coat. Tech. 258, 991-995 (2014)

16. Z.A. Wang, J.B. Chu, H.B. Zhu, Z. Sun, Y.W. Chen, S.M. Huang, Solid State Electron. 53, 1149-1153 (2009)

17. H. Ko, W. Tai, K. Kim, S. Kim, S. Suh, Y. Kim, J Cryst Growth 277, 352-358 (2005)

18. H. Liu, H. Qiu, X. Chen, M. Yu, M. Wang, Curr Appl Phys 9, 1217-1222 (2009)

19. C. Guillen, J. Herrero, Vacuum 84, 924-929 (2010)

20. E. Miorin, F. Montagner, S. Battiston, S. Fiameni, M. Fabrizio, Aip Conf. Proc. 10, 1-5 (2010)

21. K. Ellmer, R. Cebulla, R. Wendt, Surf. Coat. Technol. 98, 1251-1256 (1998)

22. W.L. Bond, Jpn. J. Appl. Phys. 36, 1674-1677 (1965)

23. S. Ilican, M. Caglar, Y. Caglar, Mat. Sc. 25, 709-718 (2007)

24. A. Zdyb, E. Krawczak, P. Lichograj, Opt. Appl. 46, 181-185 (2016) 